\title{
Evidence for Nondestructive Adsorption of Dialkyl Sulfides on Gold
}

\author{
Marcel W. J . Beulen, ${ }^{\dagger}$ Bart-Hendrik Huisman, ${ }^{\dagger}$ Peter A. van der Heijden, ${ }^{\dagger}$ \\ Frank C. J . M. van Veggel, ${ }^{\dagger}$ Marcel G. Simons, ${ }^{\ddagger}$ Ed M. E. F. Biemond, ${ }^{\prime}$ \\ Pieter J . de Lange, ${ }^{\ddagger}$ and David N. Reinhoudt*, ${ }^{\prime}$ \\ Supramolecular Chemistry and Technol ogy, MESA Research Institute, University of Twente, \\ P.O. Box 217, 7500 AE Enschede, The Netherlands, and Akzo Nobel Central Research, \\ Analytical and Environmental Chemistry Department, P.O. Box 9300, \\ 6800 SB Arnhem, The Netherlands
}

Received J uly 8, 1996. In Final Form: October 31, 1996 ${ }^{\otimes}$

\begin{abstract}
Thenondestructiveadsorption of long chain dialkyl sulfides on gold is reported. Self-assembled monolayers of decanethiol, didecyl disulfide, and didecyl sulfide were prepared and characterized by XPS, grazingangle FT-IR, wettability studies, and TOF-SIMS. The first three techniques provide evidence that wellpacked monolayers are formed. The positive SIMS spectrum of didecyl sulfide showed fragments that originate from intact dialkyl sulfide attached to gol d without $\mathrm{C}-\mathrm{S}$ bond cleavage. Our results underline the generally accepted nondestructive adsorption process of dialkyl sulfides and contradict the recently reported cleavage of one of the alkyl sulfur bonds of sulfides upon adsorption.
\end{abstract}

\section{Introduction}

Sincethe first report of monolayer assemblies on a gold surface by N uzzo and Allara, ${ }^{1}$ the nature of the binding of sulfur-containing adsorbates to gold has been discussed. It is generally accepted that alkanethiols adsorb on gold as thiolates, ${ }^{2}$ although recently adsorption as disulfides has been proposed. ${ }^{3}$ Until recently only a few examples of self-assembled monolayers of dialkyl sulfides on gold werereported. ${ }^{4}$ Wehavedescribed thesynthesis and selfassembly on gold of resorcin[4]arene(1), calix[4]arene(2), and carceplex (3) derivatives, which are bound to the gol d surface via four ${ }^{5}$ anchoring dialkylsulfide units. ${ }^{6}$ There are no indications that upon adsorption one of the $\mathrm{C}-\mathrm{S}$ bonds would be cleaved.

However, Zhong and Porter reported that sulfides, viz. phenyl ethyl sulfide and dibutyl sulfide, adsorb on gold

* Author to whom correspondence should be addressed. Fax: +31 53 4894645. Phone: + 31534892980.

† University of Twente.

‡ Akzo Nobel Central Research.

${ }^{\otimes}$ Abstract published in Advance ACS Abstracts, December 15, 1996.

(1) Nuzzo, R. G.; Allara, D. L. J . Am. Chem. Soc. 1983, 105, 44814483.

(2) UIman, A. An Introduction to UItrathin OrganicFilms; Academic Press: San Diego, CA, 1991. 1218.

(3) Fenter, P.; Eberhardt, A.; Eisenberger, P. Science1994, 266, 1216-

(4) (a) Throughton, E. B.; Bain, C. D.; Whitesides, G. M.; Nuzzo, R. G.;Allara, D. L.; Porter, M. D. Langmuir 1988, 4, 365-385. (b) Steinberg, S.; Rubinstein, I. Langmuir 1992, 8, 1183-1187. (c) Hagenhoff, B.; Benninghoven, A.; Spinke, J .; Liley, M.; Knoll, W. Langmuir 1993, 9, 1622-1624. (d) Zhang, M.; Anderson, M. R. Langmuir 1994, 10, 28072813.

(5) The use of multipoint attachment of adsorbates has also been recognized by others as advantageous for the stability of monolayers, seee.g.: (a) Adams, H.; Davis, F .; Stirling, C.J . M.J . Chem. Soc., Chem. Commun. 1994, 2527-2529. (b) Schlenoff, J. B.; Li, M.; Ly, H. J . Am. Chem. Soc. 1995, 117, 12528-12536. (c) Rojas, M. T.; Königer, R.; Stoddart, J . F.; Kaifer, A. E. J . Am. Chem. Soc. 1995, 117, 336-343.

(6) (a) Thoden van Velzen, E. U.; Engbersen, J . F.J .; Reinhoudt, D. N. Synthesis 1995, 8, 989-1008. (b) Thoden van Velzen, E. U.; Engbersen, J . F. J .; Reinhoudt, D. N. J . Am. Chem. Soc. 1994, 116, 3597-3598. (c) Schierbaum, K.-D.; Weiss, T.; Thoden van Velzen, E. U.; Engbersen, J . F. J .; Reinhoudt, D. N.; Göpel, W. Science 1994, 265, 1413-1415. (d) Thoden van Velzen, E. U.; Engbersen, J . F.J .; deL ange, P. J.; Mahy, J. W.; Reinhoudt, D. N. J . Am. Chem. Soc. 1995, 117, 6853-6862. (e) Huisman, B.-H.; Thoden van Velzen, E. U.; van Veggel, F. C. J . M.; Engbersen, J . F. J .; Reinhoudt, D. N. Tetrahedron Lett. 1995, 36, 3273-3276. (f) Huisman, B.-H.; Rudkevich, D. M.; van Veggel, F. C. J . M.; Reinhoudt, D. N. J . Am. Chem. Soc. 1996, 118, 3523-3524. as thiolates. ${ }^{7}$ They claim that one of thealkyl sulfur bonds cleaves upon adsorption on thesurface. In a recent paper ${ }^{8}$ Zhong and Porter propose that such cleavage might be a general reaction of dialkyl sulfides upon adsorption on gold. This would contradict not only our results but also those of others ${ }^{4}$ and would invalidate our current strategy toward the self-assembly of (relatively) large receptor molecules on gold. In this paper we report our experimental evidencethat dialkyl sulfides areadsorbed on gold in a nondestructive way.

\section{Experimental Procedures}

Chemicals. Decanethiol (4; RSH) was purchased from Aldrich, and didecyl disulfide (5; RSSR) and didecyl sulfide (6; RSR) were synthesi zed according to literature procedures. ${ }^{9}$ The purity of the compounds was proven by NMR and GLC $(\geq 99 \%)$, whilefast-atom-bombardment mass spectrometry (FAB-MS) was used for comparison with monolayer mass spectrometry.

Gold Substrates. Gold substrates were prepared by evaporating $200 \mathrm{~nm}$ of gold on a glass slide of $25 \mathrm{~mm}$ diameter with a $2 \mathrm{~nm}$ chromium layer for adhesion and were used immediately after evaporation.

Monolayer Preparation. All glassware used to prepare monolayers was immersed in piraña at $70^{\circ} \mathrm{C}$ for $1 \mathrm{~h}$. Warning: Piraña solution should behandled with caution; it has detonated unexpectedly. ${ }^{10} \mathrm{Next}$, the glassware was rinsed with large amounts of high-purity water (Millipore). The freshly prepared gold substrates were immersed with minimal delay into a $1 \mathrm{mM}$ adsorbate solution in ethanol for $8 \mathrm{~h}$. Subsequently, the substrates were removed from the solution and rinsed with dichloromethane, ethanol, and water to remove any physi sorbed material.

Instrumentation. For X-ray photoelectron spectroscopy (XPS) a VG Escalab 220i-XL instrument was used with a monochromatic Al K $\alpha$ X-ray source. Grazing-angle FT-IR was performed on a Biorad FTS $60 \mathrm{~A}$ spectrophotometer at an angle of incidence of $87^{\circ}$, with nitrogen purge, by co-adding 256 scans with $2 \mathrm{~cm}^{-1}$ resolution. Clean substrates were used as a background. The contact angle measurements were measured with a home-made videosystem which records the growth and shrinkage of solvent droplets $(1-2 \mu \mathrm{L})$ via a small syringe. At

(7) Zhong, C.-J .; Porter, M. D. J . Am. Chem. Soc. 1994, 116, 1161611617.

(8) Zhong, C.-J .; Porter, M. D. Anal. Chem. 1995, 67, 709A-715A.

(9) (a) McAllan, D. T.; Cullum, T. V.; Dean, R. A.; Fidler, F. A.J . Am. Chem. Soc. 1951, 73, 3627-3632. (b) Masuda, Y.; Hoshi, M.; Nunokawa, Y.; Arase, A. J . Chem. Soc., Chem. Commun. 1991, 1444-1445.

(10) (a) Dobbs, D. A.; Bergman, R. G.; Theopold, K. H. Chem. Eng. News 1990, 68 (17), 2. (b) Wnuk, T. Chem. Eng. News 1990, 68 (26), 2. (c) Matlow, S. L. Chem. Eng. News 1990, 68 (30), 2. 

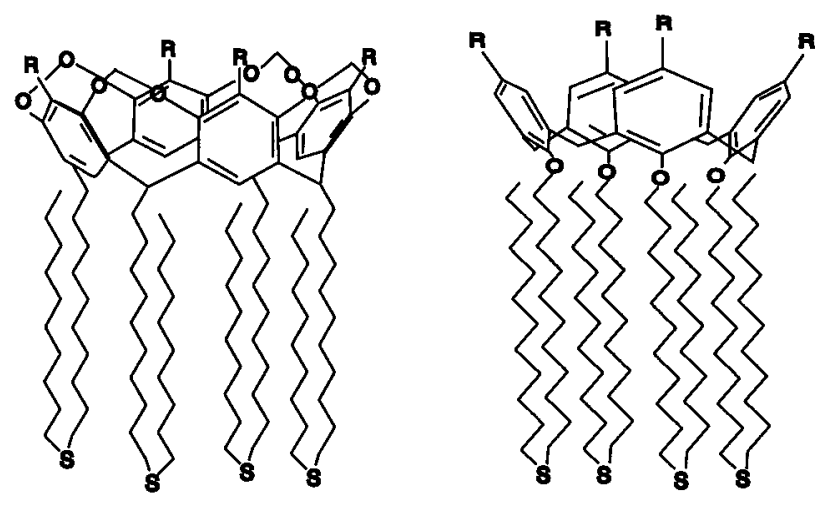

Resorcin[4]arene adsorbate

1 a: $R=H$ b: $R=M e$ c: $\mathbf{R}=\mathrm{Br}$

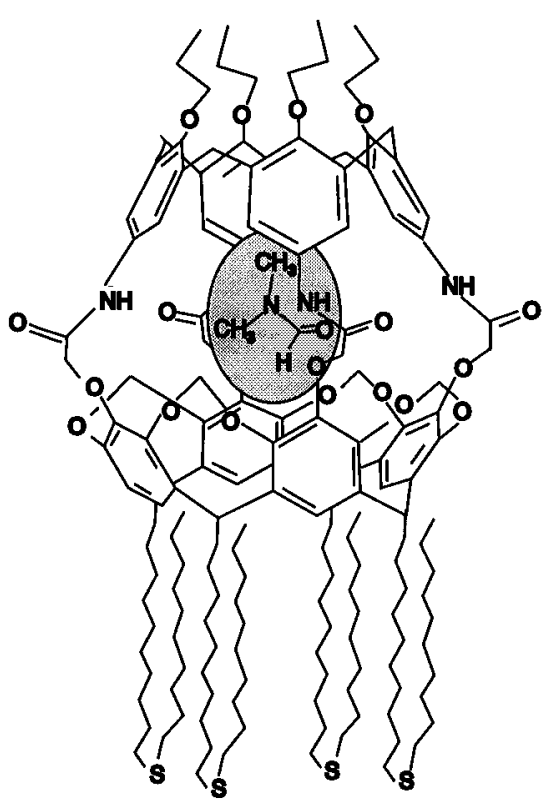

Carceplex

3

the moments of expansion and contraction a photograph was made, and the contact angle was determined from the photograph.11 The time-of-flight secondary ion mass spectrometry (TOF-SIMS) spectra were acquired with a VG IX23LS time-offlight instrument with a pulsed primary beam of $\mathrm{Ga}^{+}$ions (30 $\mathrm{keV}$ ) under 'static' conditions.

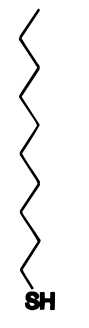

4

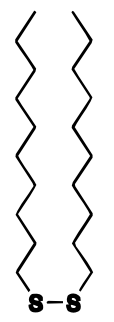

5

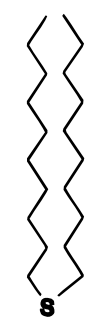

6
Results and Discussion

Self-assembled monolayers of decanethiol (4), didecyl disulfide (5), and didecyl sulfide (6) were prepared and

(11) Sondag-Huethorst, J . A. M.; Fokkink, L. G. J . Langmuir 1992, 8, 2560-2566.
Table 1. Characteristic C-H Stretching Modes ${ }^{\mathrm{a}}\left(\mathrm{cm}^{-1}\right)$

\begin{tabular}{lccccc}
\hline \multirow{2}{*}{ adsorbate } & \multicolumn{2}{c}{$\mathrm{CH}_{2}$} & & \multicolumn{2}{c}{$\mathrm{CH}_{3}$} \\
\cline { 2 - 3 } \cline { 5 - 6 } & $v_{\mathrm{a}}$ & $v_{\mathrm{s}}$ & & $v_{\mathrm{s}}(\mathrm{ip})$ & $v_{\mathrm{s}}(\mathrm{FR})$ \\
\hline decanethiol & 2922 & 2853 & & 2965 & 2877 \\
didecyl disulfide & 2924 & 2855 & & 2966 & 2881 \\
didecyl sulfide & 2926 & 2855 & & 2967 & 2881
\end{tabular}

a $v_{\mathrm{a}}$ and $v_{\mathrm{s}}$ are the asymmetrical and symmetrical stretching modes, ip is in-plane vibration, and FR is Fermi resonance.

Table 2. Contact Angles of the Assemblies on Gold with Water

\begin{tabular}{lcc}
\hline \multicolumn{1}{c}{ adsorbate } & $\theta_{\mathrm{a}}\left(\mathrm{H}_{2} \mathrm{O}\right.$, deg $)$ & $\theta_{\mathrm{r}}\left(\mathrm{H}_{2} \mathrm{O}, \mathrm{deg}\right)$ \\
\hline decanethiol & $108 \pm 2$ & $91 \pm 1$ \\
didecyl disulfide & $106 \pm 3$ & $92 \pm 2$ \\
didecyl sulfide & $103 \pm 3$ & $91 \pm 2$
\end{tabular}

characterized by XPS, grazing-incidence FT-IR, wettability studies, and time-of-flight secondary ion mass spectrometry (TOF-SIMS). XPS showed the presence of the elements carbon and sulfur in the monolayer. ${ }^{12} \mathrm{No}$ distinct differences in the $S\left(2 p_{3 / 2}\right)$ peak positions for the three monolayers are found; all three monol ayers exhibit a signal for $\mathrm{C}(1 \mathrm{~s})$ at $284.8 \mathrm{eV}$ and for $\mathrm{S}\left(2 \mathrm{p}_{3 / 2}\right)$ at $161.9-$ $162.0 \mathrm{eV} .{ }^{13}$ Since no profound differences in the $S\left(2 \mathrm{p}_{3 / 2}\right)$ peak position between the neat thiol and sulfide compounds are reported, ${ }^{14}$ no conclusions based on XPS peak positions can be drawn with regard to the adsorption process. The IR spectra show the alkyl stretches in the $2970-2850 \mathrm{~cm}^{-1}$ region (Table 1). Theasymmetrical and symmetrical $\mathrm{CH}_{2}$ stretch vibrations for a decanethiol monolayer (4) have been reported, which indicates a more crystalline-like monolayer in that case. ${ }^{15}$ Wettability studies with water revealed high advancing contact angles and a small hysteresis between theadvancing and receding contact angles for all monolayers (Table 2). The contact angles are slightly smaller by approximately $5^{\circ}$ than reported for monolayers of $\mathbf{4 - 6 , 4 a , 1 6}$ but the hysteresis (an important measure for the degree of order of the monolayer) is in the same range $\left(10-15^{\circ}\right)$. These three techniques provide ample evidence that well-packed monolayers were formed. The positive SI MS spectra of 4-6 (Figure 1) show profound differences between monolayers of didecyl sulfide and decanethiol or didecyl disulfide. The SIMS spectrum of didecyl sulfide clearly shows major peaks at $\mathrm{m} / \mathrm{z}=511(\mathrm{M}+\mathrm{Au})^{+}$, at $\mathrm{m} / \mathrm{z}=313$ $(\mathrm{M}-\mathrm{H})^{+}$, and at $\mathrm{m} / \mathrm{z}=509(\mathrm{M}+\mathrm{Au}-2 \mathrm{H})^{+}$. These peaks originate from intact dialkyl sulfide attached to gold without $\mathrm{C}-\mathrm{S}$ bond cleavage. In the spectra of the thiol and disulfide monolayers no peaks are observed at these positions. ${ }^{17}$ In addition in the SIMS spectrum of

(12) I mmediateXPS measurements showed noother elements besides Au, C, and S. After two weeks, measurements of thesamesampleshowed oxidation for all three different types of monolayers, as was visualized by the presence of an $\mathrm{O}(1 \mathrm{~s})$ signal at $531.8 \mathrm{eV}$ and additional sulfur peaks $\left(\mathrm{S}[\mathrm{O}]_{\mathrm{n}}\right)$ at 168.5 and $169.5 \mathrm{eV}$. We havesomeindications that this is induced by light. A recent detailed paper has appeared on this subject: Hutt, D. A.; Leggett, G. J .J . Phys. Chem. 1996, 100, 66576662.

(13) XPS (eV). S(2 $\left.p_{3 / 2}\right):$ RSH, $162.0 \pm 0.2 ; R S S R, 161.9 \pm 0.2 ; R S R$ $161.9 \pm 0.2$. C(1s): RSH, $284.8 \pm 0.2 ;$ RSSR, $284.8 \pm 0.2 ; R S R, 284.8$ \pm 0.2 . The $S\left(2 \mathrm{p}_{1 / 2}\right)$ peaks are located about $1.2 \mathrm{eV}$ higher in binding energy.

(14) (a) Wagner, C. D.; Riggs, W. M.; Davis, L. E.; Moulder, J . F. In Handbook of X-Ray Photoel ectron Spectroscopy; Muilenberg, G. E., Ed.; Perkin-Elmer Corporation: Eden Prairie, Minnesota, 1979; p 56. (b) Lindberg, B. J .; Hamrin, K.; J ohansson, G.; Gelius, U .; Fahlmann, A.; Nordling, C.; Siegbahn, K. Phys. Scr. 1970, 1, 286-298.

(15) This study: 2922 and $2853 \mathrm{~cm}^{-1}$, compared with 2920 and 2851 $\mathrm{cm}^{-1}$ (Porter, M. D.; Bright, T. B.; Allara, D. L.; Chidsey, C. E. D. J . Am. Chem. Soc. 1987, 109, 3559-3568). These differences may be caused by small differences in preparation. This does, however, not affect the conclusions of this paper.

(16) Biebuyck, H. A.; Bain, C. D.; Whitesides, G. M. Langmuir 1994, 10, 1825-1831. 

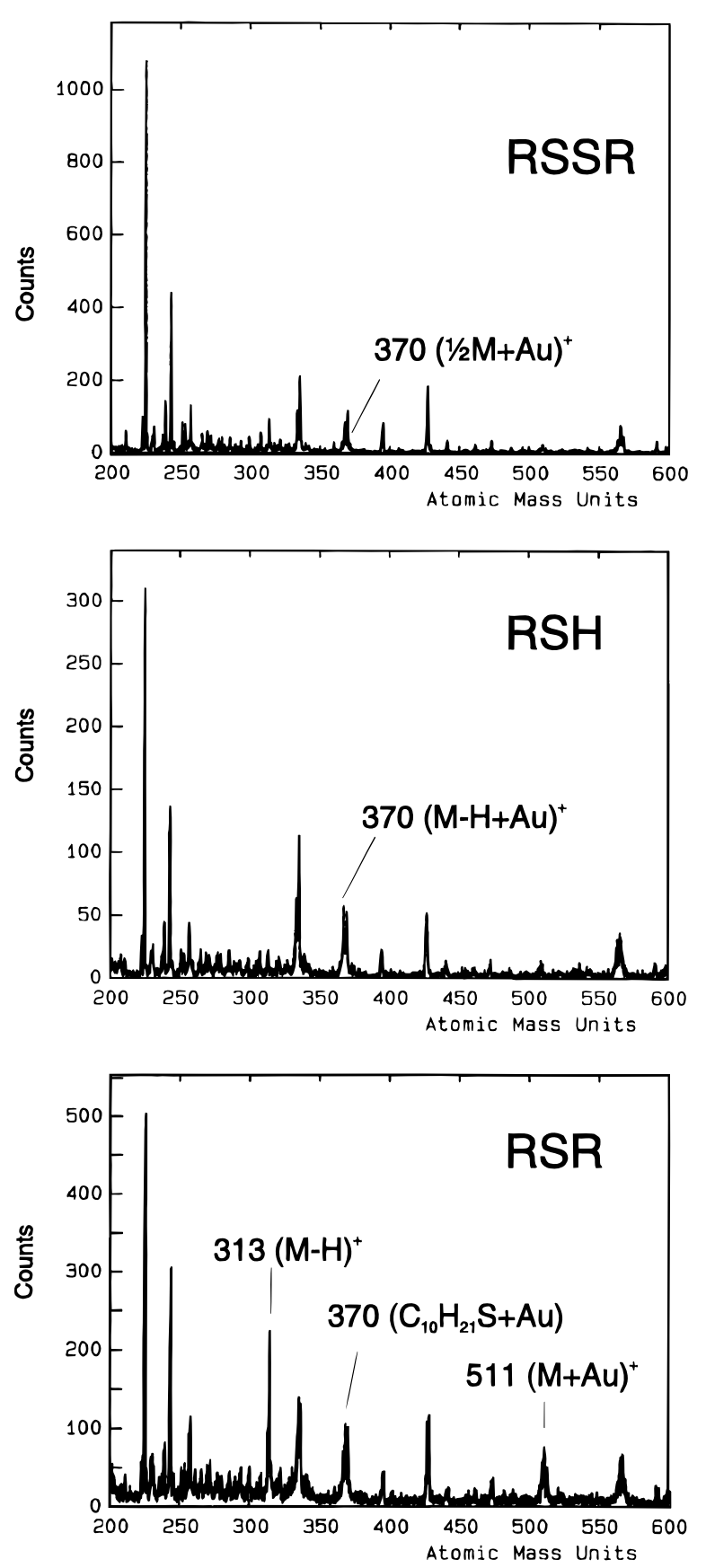

Figure 1. Positive TOF-SIMS spectra of self-assembled monolayers of decanethiol (4), didecyl disulfide (5), and didecyl sulfide (6).

the didecyl sulfide monolayer a fragment is observed at $\mathrm{m} / \mathrm{z}=370\left(\mathrm{C}_{10} \mathrm{H}_{21} \mathrm{~S}+\mathrm{Au}\right)^{+}{ }^{18}$ which corresponds to the fragment $\mathrm{m} / \mathrm{z}=173\left(\mathrm{C}_{10} \mathrm{H}_{21} \mathrm{~S}\right)^{+}$in the $\mathrm{FAB}-\mathrm{MS}$ spectrum

(17) Other peaks in SIMS are tentatively assigned: $\mathrm{m} / \mathrm{z}=225$ $(\mathrm{AuCO})^{+}, 243\left(\mathrm{AuSCH}_{2}\right)^{+}, 394\left(\mathrm{Au}_{2}\right)^{+}, 427\left(\mathrm{Au}_{2} \mathrm{SH}\right)^{+}$, and 566 $\left(\mathrm{Au}_{2} \mathrm{C}_{10} \mathrm{H}_{20} \mathrm{~S}\right)^{+}$. of the neat sulfide $\mathbf{6}$. As expected, also in the spectra of decanethiol (4) and the didecyl disulfide (5) monolayer this peak at $\mathrm{m} / \mathrm{z}=370$ is present, which in those cases corresponds to the adsorbed species plus one gold atom. Previous SIMS measurements of a resorcin[4]arene monolayer also revealed the $(M+A u)^{+}$peak, which confirms the nondestructive adsorption of dialkyl sulfide adsorbates. ${ }^{19}$ Additionally, also Hagenhoff et al . ${ }^{4 c}$ recently reported SIMS measurements with monolayers of the dialkyl sulfide $\mathrm{S}\left(\left(\mathrm{CH}_{2}\right)_{11} \mathrm{OH}\right)_{2}$ and found the $(\mathrm{M}+\mathrm{Au})^{+}$ peak in the positive SIMS spectrum of the monolayer; this was interpreted as theattachment of theintact sulfide molecule. ${ }^{20}$

These results are in sharp contrast to the recent conclusion by Zhongand Porter that in phenyl ethyl sulfide and dibutyl sulfide the $\mathrm{C}-\mathrm{S}$ bond cleaves. Their only evidence for the bond cleavage comes from reductive desorption measurements, viz. the observation of two desorption peaks for phenyl ethyl sulfide (at -0.57 and $-0.67 \mathrm{~V}_{\mathrm{Ag} / \mathrm{AgCl}}$ ), like in the individual desorption of monolayers of thiophenol and ethanethiol (peaks at -0.57 and $-0.68 \mathrm{~V}_{\mathrm{Ag} / \mathrm{AgCl}}$, respectively). However, it should be emphasized that these data were obtained under destructiveconditions (removal of the monolayer at very negative potentials and strong alkaline conditions [0.5 $\mathrm{M} \mathrm{KOH}]$ ). Under these severe conditions, $\mathrm{C}-\mathrm{S}$ bond cleavage may well occur and this might explain the two peaks in the reductive sweep. ${ }^{21}$

In conclusion, self-assembled monol ayers of decanethiol, didecyl sulfide, and didecyl disulfide were compared by means of XPS, grazing-angle FT-IR, and wettability, showing no distinct differences. Profound differences between the three monolayers were, however, shown by mass spectrometry. TOF-SI MS measurements gavedirect chemical evidence for the nondestructive adsorption of long chain dialkyl sulfides on gold.

Acknowledgment. We thank Dr. L. G. J . Fokkink (Philips Research Laboratories Eindhoven) for providing equipment for wettability studies.

\section{LA9606660}

(18) Benninghoven, A. Angew. Chem., Int. Ed. Engl . 1994, 33, 10231043.

(19) As part of other studies we have recently also found for a nonsymmetrical sulfide, 12-thiadocosyl isonicotinoate $\left(4-\left[\mathrm{C}_{5} \mathrm{H}_{5} \mathrm{~N}\right]-\right.$ $\left.\mathrm{C}(\mathrm{O}) \mathrm{O}\left(\mathrm{CH}_{2}\right)_{11} \mathrm{~S}\left(\mathrm{CH}_{2}\right)_{9} \mathrm{CH}_{3}\right)$, a molecular peak at $\mathrm{m} / \mathrm{z}=646(\mathrm{M}+\mathrm{Au})^{+}$ in SIMS. This provides additional evidence for the nondestructive adsorption of sulfides.

(20) This evidencefor thenondestructiveadsorption of dialkyl sulfides on gold confirms our previous work (see ref $6 \mathrm{~d}$ ); viz., the degree of order of resorcin[4]arene adsorbates is strongly dependent on the length and number of theterminal al kyl chains of thedialkyl sulfidemoiety, firstly, because equal lengths of both alkyl chains fill the area underneath the resorcin[4]areneheadgroup al most perfectly and, secondly, because the optimal monolayers are indeed obtained from adsorbates that have headgroups smaller or equal to the cross-sectional area occupied by eight supporting al kyl chains $\left(\leq 160 \AA^{2}\right)$. These results for the resorcin[4]arenemonolayers cannot beeasily explained when thedialkyl sulfides would be cleaved upon adsorption.

(21) Simonet, J . In Supplement S: The chemistry of sulphurcontaining functional groups; Patai, S., Rappoport, Z., Eds.; J ohn Wiley \& Sons Ltd: New York, 1993; pp 439-493. 